\title{
Routine follow up of breast cancer in primary care: randomised trial
}

Eva Grunfeld, David Mant, Patricia Yudkin, Ruth Adewuyi-Dalton, David Cole, Jill Stewart, Ray Fitzpatrick, Martin Vessey

\begin{abstract}
Objective-To assess the effect on time to diagnosis of recurrence and on quality of life of transferring primary responsibility for follow up of women with breast cancer in remission from hospital to general practice.

Design-Randomised controlled trial with 18 month follow up in which women received routine follow up either in hospital or in general practice.

Subjects and setting-296 women with breast cancer in remission receiving regular follow up care at district general hospitals in England.

Main outcome measures-Time between first presentation of symptoms to confirmation of recurrence; quality of life measured by specific dimensions of the SF-36 schedule, the EORTC symptom scale, and hospital anxiety and depression scale.
\end{abstract}

Results-Most recurrences $(18 / 26,69 \%)$ presented as interval events, and almost half (7/16, $44 \%$ ) of the recurrences in the hospital group presented first to general practice. The median time to hospital confirmation of recurrence was 21 days in the hospital group (range 1-376 days) and 22 days in the general practice group (range 4-64). The differences between groups in the change in SF-36 mean scores from baseline were small: -1.8 (95\% confidence interval -7.2 to 3.5 ) for social functioning, $0.5(-4.1$ to 5.1$)$ for mental health, and $0.6(-3.6$ to 4.8$)$ for general health perception. The change from baseline in the mean depression score was higher in the general practice group at the mid-trial assessment (difference $0.6,0.1$ to 1.2 ) but there was no significant difference between groups in the anxiety score or the EORTC scales.

Conclusion-General practice follow up of women with breast cancer in remission is not associated with increase in time to diagnosis, increase in anxiety, or deterioration in health related quality of life. Most recurrences are detected by women as interval events and present to the general practitioner, irrespective of continuing hospital follow up.

\section{Introduction}

Routine follow up after completion of primary treatment for breast cancer is standard practice in most countries. ${ }^{12}$ It usually entails visits to hospital outpatient clinics for as many as 10 years after diagnosis and includes history taking, physical examination, blood tests, imaging, and mammography. ${ }^{34}$ Recently there has been much controversy surrounding this practice. $^{5-7}$ Most recurrences are detected by patients themselves, who frequently present at unscheduled visits in the interval between follow up appointments. ${ }^{8-12}$ Two randomised trials designed to evaluate the benefit of routine investigations as part of follow up have shown that a less intensive surveillance regimen (consisting only of history taking, physical examination, and mammography) can be adopted without jeopardising survival or health related quality of life. ${ }^{13} 14$

There has been a call for a reappraisal of routine follow up, ${ }^{15}$ and alternatives to hospital outpatient clinics have been proposed. ${ }^{16}{ }^{17}$ In countries with a strong primary care base one alternative is to give responsibility for routine follow up to the general practitioner, with the option to reinitiate specialist hospital care if problems develop. General practitioners have expressed a willingness to undertake this responsibility. ${ }^{18}{ }^{19} \mathrm{We}$ report here the results of a randomised controlled trial to evaluate the effect of such a primary care based system of routine breast cancer follow up on time to diagnosis of recurrence and on health related quality of life.

\section{Participants and methods}

SUBJECTS AND SETTING

All participants were women with breast cancer in remission undergoing hospital follow up at two district general hospitals in England. Both hospitals serve a mixed urban-industrial and rural population. Ethical approval to conduct the study was obtained from the local research ethics committees. The names of all patients diagnosed as having breast cancer within the previous five years (roughly 1988-92) were obtained from local cancer registries. The hospital records of these patients were then reviewed to determine who was eligible. The eligibility criteria were: initial stage I, II, or III breast cancer; no distant metastases; primary treatment completed at least three months previously (including any complications of primary treatment); still attending outpatient clinics for routine follow up; and no evidence of disease at last follow up visit. Altogether 445 eligible patients were identified.

\section{RANDOM ALLOCATION}

Eligible patients were invited to participate by letter and were asked to send a signed consent form to the research nurse at their centre. Those who agreed were randomised to one of two groups: continued routine follow up in outpatient clinics according to usual practice (hospital group) or routine follow up from their own general practitioner (general practice group). Follow up groups were assigned by a telephone call to the trial coordination centre in Oxford. Random allocation was in blocks of eight. Of the $\mathbf{4 4 5}$ eligible patients $296(66.5 \%)$ agreed to participate in the study, but 121 of the 149 non-participants $(81.2 \%)$ completed the baseline assessment. Participants were younger than non-participants (mean age $60.7 v 64.3$ years) and fewer had stopped full time education at or before the age of $16(82.4 \% v 91.4 \%)$. There were no important differences between participants and non-participants in any clinical characteristic or in the baseline scores of any of the subscales of the quality of life instruments (see over). 
Table 1-Baseline characteristics of participants by trial group. Values are numbers (percentages) of patients unless stated otherwise

\begin{tabular}{lcc}
\hline & $\begin{array}{c}\text { General } \\
\text { practice }\end{array}$ & Hospital \\
\hline No of patients & 148 & 148 \\
Mean (SD) age & $59.1(10.3)$ & $62.4(12.0)$ \\
Mean (SD) age at diagnosis & $55.6(10.6)$ & $59.0(12.0)$ \\
Mean (SD) time since diagnosis & $3.4(1.8)$ & $3.4(1.7)$ \\
Stage at diagnosis: & & \\
Stage I & $60(40.5)$ & $75(50.6)$ \\
Stage II & $80(54.1)$ & $69(46.6)$ \\
Stage III & $8(5.4)$ & $4(2.7)$ \\
Type of surgery: & & \\
Mastectomy & $74(50.0)$ & $79(53.4)$ \\
Breast conservation surgery & $73(49.3)$ & $65(43.9)$ \\
Other & $1(0.7)$ & $4(2.7)$ \\
Adjuvant treatment received: & $105(71.0)$ & $99(66.9)$ \\
Radiotherapy & $8(5.4)$ & $4(2.7)$ \\
Chemotherapy & $78(52.7)$ & $88(59.4)$ \\
Tamoxifen & & \\
\hline
\end{tabular}

A total of 115 general practitioners had at least one patient allocated to general practice follow up. Of these, two $(1.7 \%)$ refused to provide follow up, citing lack of resources and of time to do the paperwork. The maximum number of patients allocated to general practice follow up registered with any one practitioner was four. Of the 148 participants randomised to the general practice group, $141(95.7 \%)$ received the intervention as allocated, $5(3.4 \%)$ referred themselves back to hospital, and $2(1.4 \%)$ were registered with general practitioners who had refused to provide follow up. Of the 148 participants randomised to the hospital group, 5 (3.4\%) requested discharge to general practice follow up so that $143(96.6 \%)$ received the intervention as allocated. One $(0.7 \%)$ participant in each group moved out of the district and was lost to follow up.

The comparability of the women allocated to each study group by randomisation is shown in table 1 . The general practice group was younger at diagnosis (mean age $55.6 v 59.0$ years) and at entry to the study (mean age $59.1 v 62.4$ years). There were more stage I patients in the hospital group ( $50.3 \% v 40.4 \%)$. Otherwise the two groups were very similar in clinical characteristics and in baseline scores on all subscales of the quality of life instruments.

\section{FOLLOW UP SCHEDULE}

The recommended frequency of routine visits in general practice was the same as for women remaining in hospital follow up and depended on the time since breast cancer had been diagnosed. In one hospital the recommended follow up schedule after diagnosis was every three months for year 1, every six months for years 2-5, and every year thereafter; in the other it was every three, four, and six months for years 1,2 , and 3 respectively and every year thereafter. Mammography was recommended routinely every 12-36 months in one hospital (depending on initial treatment and age). For patients in the general practice group from this hospital all routine and diagnostic mammograms were initiated by the general practitioner. In the other hospital mammography was recommended routinely one year after completion of primary treatment and then every two years. Routine mammograms were organised through the breast cancer screening office and patients were recalled at the appropriate interval, but diagnostic mammography was initiated by the general practitioner for patients in the general practice group. All other investigations were recommended only if clinically indicated.

INFORMATION GIVEN TO GENERAL PRACTITIONERS

A "discharge" letter was sent by the hospital consultant to the general practitioner about each patient discharged to general practice care outlining the patient's breast cancer history, describing the follow up routine recommended, and assuring the general practitioner that rapid rereferral was possible if any problems developed. The letter was accompanied by an educational handbook on breast cancer follow up care.

\section{OUTCOME MEASURES AND SAMPLE SIZE}

The main clinical outcome assessed was time to diagnosis of recurrence. Data were abstracted on the mode of presentation (at a routine follow up appointment or in the interval in between follow up visits), the nature of the recurrence (local, regional, or distant), and the sequence of clinical events. Local recurrence was defined as recurrence in the remaining breast tissue or chest wall, while regional recurrence was recurrence in the ipsilateral lymph nodes. Two key index dates were determined: the date of first presentation of the symptom or sign heralding the recurrence to a doctor and the date on which the recurrence was confirmed by a hospital specialist. The time to diagnosis reported is the difference between these two index dates.

The effect of follow up on health related quality of life was assessed by three self administered instruments: the British version of the SF- $36,{ }^{20}$ the European Organisation for Research and Treatment of Cancer core quality of life questionnaire (EORTC QLQ-C30), ${ }^{21}$ and the hospital anxiety and depression scale. ${ }^{22}$

The trial was designed to detect a mean time to diagnosis between allocation groups of 3 months (standardised difference 1.2). To achieve $90 \%$ power with $\alpha=0.05$ we estimated that 30 recurrences would be required. ${ }^{23}$ Assuming an annual recurrence rate of about $7 \%,{ }^{24}$ this would require a sample size of 300 , with follow up planned for 18 months. At the end of the 18 month follow up period all surviving patients were contacted by post and asked to complete a form listing any problems related to breast cancer that had developed during the study period to ensure complete recording of all important clinical events which had occurred in both hospital and general practice groups.

\section{DATA COLLECTION}

Clinical data were collected prospectively at both hospital and general practice visits by means of a record of visit form. This was completed at all consultations possibly related to breast cancer by doctors for patients in both groups. This form was a checklist of signs, symptoms, and investigations ordered at the time of the visit. For patients developing clinical problems suggesting possible recurrence we obtained further data by writing to the general practitioner, reviewing hospital records, and (for deceased patients) obtaining records from the family health services authority. All clinical information on patients with suspected recurrence (record of visit forms, hospital notes, test results, doctors' correspondence) was assessed independently by three of the authors and any discrepancies or difficulties discussed. The information was masked as far as possible with respect to allocation group so that "time to diagnosis" was assessed in a blinded fashion. In some cases, however, the allocation group could have been deduced from the course of clinical events.

Health related quality of life was assessed at three points in the trial: baseline, mid-trial, and at the end of the trial. The mid-trial questionnaire was sent within 10 days of a breast cancer follow up visit and took place between months 6 and 12. Questionnaires were posted to study participants, and one reminder letter was sent if the questionnaire had not been returned within two weeks. After the denominator was adjusted for patients who had died or gone away, the response rates in the general practice and hospital groups respectively were 
Table 2-Clinical presentation of women with recurrence by trial group

\begin{tabular}{|c|c|c|c|c|c|}
\hline $\begin{array}{l}\text { Case } \\
\text { No }\end{array}$ & $\begin{array}{l}\text { Type of } \\
\text { recurrence }\end{array}$ & Presenting problem & $\begin{array}{l}\text { First } \\
\text { presented } \\
\text { to }\end{array}$ & $\begin{array}{c}\text { Routine or } \\
\text { interval } \\
\text { visit }\end{array}$ & $\begin{array}{l}\text { Time to } \\
\text { diagnosis } \\
\text { (days) }\end{array}$ \\
\hline \multicolumn{6}{|c|}{ General practice group } \\
\hline $1^{*}$ & Metastastic & Vaginal bleeding & GP & Interval & 64 \\
\hline $2^{*}$ & Metastastic & Shortness of breath & GP & Interval & 10 \\
\hline 3 & Regionalt & Ipsilateral neck node & GP & Routine & 4 \\
\hline 4 & Local & Pain and nodule on scar & GP & Interval & 28 \\
\hline 5 & Locoregional & Abnormal mammogram & GP & Routine & 14 \\
\hline 6 & Local & Chest wall nodule & GP & Routine & 32 \\
\hline 7 & Metastastic & Hip pain & GP & Interval & 10 \\
\hline 8 & Local & Abnormal mammogram & GP & Routine & 51 \\
\hline 9 & Metastastic & Leg and hip pain & GP & Interval & 16 \\
\hline 10 & Metastastic & Cough & GP & Interval & 58 \\
\hline \multicolumn{6}{|c|}{ Hospltal group } \\
\hline $11^{*}$ & Metastastic & Fatigue and shortness of breath & GP & Interval & 23 \\
\hline $12^{*}$ & Metastastic & General malaise & GP & Interval & 22 \\
\hline 13 & Regional & Ipsilateral axillary node & Hospital & Interval & 9 \\
\hline $14^{*}$ & Metastastic & Haemoptysis & GP & Interval & 19 \\
\hline 15 & Regional & Ipsilateral neck node & GP & Interval & 21 \\
\hline 16 & Metastastic & Shoulder pain & Hospital & Interval & 21 \\
\hline $17^{*}$ & Metastastic & Abdominal pain & GP & Interval & 23 \\
\hline 18 & Metastastic & Hip fracture & Hospitalł & Interval & 18 \\
\hline $19^{*}$ & Metastastic & Hip pain & Hospital & Interval & 1 \\
\hline $20^{*}$ & Metastastic & General malaise & Hospital & Routine & 151 \\
\hline $21^{*}$ & Metastastic & Bone pain & Hospital & Routine & 376 \\
\hline 22 & Regionalt & Ipsilateral axillary node & Hospital & Routine & 19 \\
\hline 23 & Metastastic & Hip pain & Hospital & Interval & 2 \\
\hline 24 & Local & Ipsilateral breast lump & Hospital & Unknown & 10 \\
\hline 25 & Metastastic & Cough & GP & Interval & 44 \\
\hline \multirow[t]{2}{*}{26} & Metastastic & General malaise and shortness & & & \\
\hline & & of breath & GP & Interval & 36 \\
\hline
\end{tabular}

GP = general practitioner.

"Died of problems related to breast cancer.

†Distant disease subsequently detected by further investigation.

$\ddagger$ Accident and emergency department.

Table 3-Sequence of clinical events in patients with diagnostic delays of 28 days or more

\begin{tabular}{|c|c|c|}
\hline $\begin{array}{l}\text { Case } \\
\text { No }\end{array}$ & $\begin{array}{l}\text { Delay } \\
\text { (days) }\end{array}$ & Sequence of events \\
\hline 1 & 64 & $\begin{array}{l}\text { Patient initiated visit to GP with recurrence of postmenopausal bleeding after a } \\
\text { dilatation and curretage } 5 \text { months earlier; } 26 \text { day interval between GP referral and } \\
\text { outpatient appointment; further } 30 \text { day interval between appointment and } \\
\text { examination under anaesthesia and biopsy }\end{array}$ \\
\hline 4 & 28 & $\begin{array}{l}\text { Patient initiated visit to GP with nodule on scar and pain; interval to referral to } \\
\text { oncologist } 4 \text { days; interval to outpatient clinic appointment } 23 \text { days }\end{array}$ \\
\hline 6 & 32 & $\begin{array}{l}\text { Nodule on mastectomy scar noted by GP at routine follow up. Interval to surgical } \\
\text { outpatient clinic appointment } 25 \text { days; interval to confirmation of result of fine } \\
\text { neөdle aspiration } 5 \text { days }\end{array}$ \\
\hline 8 & 51 & $\begin{array}{l}\text { Routine mammography organised by GP gave positive results; interval between report } \\
\text { received by GP and date of referral letter } 30 \text { days; interval until seen by surgeon } \\
5 \text { days; interval from outpatient clinic appointment to written confirmation of } \\
\text { diagnosis of local recurrence } 15 \text { days }\end{array}$ \\
\hline 10 & 58 & $\begin{array}{l}\text { Patient initiated visit to GP with dry cough and skin lesion. Immediate referral of skin } \\
\text { lesion to dermatologist but urgent appointment not requested; } 29 \text { days till patient } \\
\text { reattended with persistent cough; chest radiography performed: distant disease } \\
\text { considered but further } 18 \text { days elapsed until repeat radiography after antibiotic } \\
\text { treatment; referral at this point but further } 10 \text { days before diagnosis confirmed }\end{array}$ \\
\hline 20 & 151 & $\begin{array}{l}\text { Routine hospital appointment: unexplained deterioration in general health noted and } \\
\text { reported to GP in letter; no further investigation until sudden deterioration } 6 \text { months } \\
\text { later precipitated urgent hospital admission; widespread distant disease diagnosed }\end{array}$ \\
\hline 21 & 376 & $\begin{array}{l}\text { Complained of bone pain at routine hospital appointment; bone scan showed } \\
\text { increased isotope uptake but assessed as probably degenerative rather than distant } \\
\text { cause; bone pain reported again at appointment } 1 \text { year later; repeat bone scan } \\
\text { showed widespread metastases }\end{array}$ \\
\hline 25 & 44 & $\begin{array}{l}\text { Presented to GP with cough; } 6 \text { days until chest radiography report of small pleural } \\
\text { effusion; } 23 \text { days until repeat chest radiogram showed new nodular opacities; } \\
6 \text { days until referral and further } 7 \text { days before hospital appointment and confirmation }\end{array}$ \\
\hline 26 & 36 & $\begin{array}{l}\text { Self referred to GP with general malaise and shortness of breath; phone call and } \\
\text { referral letter from GP within } 5 \text { days; } 12 \text { days until computed tomography, which } \\
\text { gave negative results except for pleural effusion; } 18 \text { day interval before effusion } \\
\text { tapped and malignant cells confirmed }\end{array}$ \\
\hline
\end{tabular}

GP = general practitioner.
$99.3 \%(147 / 148)$ and $95.3 \%(141 / 148)$ at baseline, $97.2 \%(140 / 144)$ and $88.7 \%(126 / 142)$ at mid-trial, and $97.2 \%(137 / 141)$ and $88.1 \%(119 / 135)$ at the end of the trial.

\section{STATISTICAL ANALYSIS}

Confidence intervals were calculated using the statistical programme CIA. ${ }^{25}$ The two tailed $t$ test was used to assess the significance of differences between mean scores on the quality of life subscales. Difference in time to diagnosis was tested by the two tailed Mann-Whitney U test.

\section{Results}

\section{CLINICAL DIAGNOSIS}

During the 18 months of the study $26(8.8 \%)$ women presented with a recurrence of breast cancer, 10 in the general practice group $(10 / 148,6.8 \%)$ and 16 in the hospital group $(16 / 148,10.8 \%)$. There were $9(6.1 \%)$ deaths related to breast cancer, $2(1.4 \%)$ in the general practice group and $7(4.7 \%)$ in the hospital group. Of the 26 women, $4(15.4 \%)$ presented with local, 5 $(19.2 \%)$ with regional, and $17(65.4 \%)$ with distant recurrence (table 2). In two of the patients who presented initially with regional recurrence, distant recurrence was subsequently detected. Distant recurrence occurred in $6 / 148(4.1 \%)$ of the general practice group compared with $13 / 148(8.8 \%)$ in the hospital group (difference $4.7 \%$; $95 \%$ confidence interval -0.8 to 10.3). The person who initiated the first medical contact which led to the diagnosis of recurrence was ascertainable for 25 women: in most cases $(18 / 25,72 \%)$ the woman herself identified an abnormality and presented it between routine visits. Most of these interval visits were made to the general practitioner, $100 \%$ $(6 / 6)$ in the general practice group and $58 \%(7 / 12)$ in the hospital group.

The median time to hospital confirmation of recurrence was 21 days in the hospital group (range 1-376 days) and 22 days in the general practice group (range 4-64 days). The median difference in time to diagnosis was 1.5 days ( -13 to 22 ). Most cases of recurrence were confirmed in less than 28 days from first presentation. Clinical details of the diagnostic process in the five women in the general practice group and four women in the hospital group for whom time to diagnosis was $\mathbf{2 8}$ days or more are reported in table 3.

\section{HEALTH RELATED QUALITY OF LIFE}

Data on quality of life are presented in table 4. A positive change in the SF-36 subscales reported indicates an improvement in quality of life. Conversely, a positive change in the symptom subscales and the depression and anxiety scales indicates an increase in symptoms and a presumed deterioration in quality of life. The differences between groups in the change in mean scores from baseline were uniformly small both at the trial midpoint (shortly after a follow up visit) and at the end of the trial. The change from baseline in the mean anxiety and depression score was higher in the general practice group at the mid-trial assessment (difference $0.6,0.1$ to 1.2 ) but there was no significant difference between groups in the anxiety and depression score. There were no differences between groups in caseness on the anxiety and depression scale. The proportion of cases of anxiety at baseline, mid-trial, and trial end, respectively, was $11.0 \%$ (16/146), $11.8 \%$ (16/ $136)$, and $13.3 \%(17 / 128)$ in the general practice group and $7.9 \%(11 / 139), 8.0 \%(10 / 125)$, and $9.5 \%(11 / 116)$ in the hospital group. The proportion of cases of depression was $3.5 \%(5 / 144), 3.7 \%(5 / 135)$, and $4.5 \%$ $(6 / 134)$ in the general practice group and $2.9 \%(4 / 140)$, $3.3 \%(4 / 123)$, and $4.2 \%(5 / 118)$ in the hospital group. 


\begin{tabular}{|c|c|c|c|c|c|c|c|c|}
\hline & \multicolumn{2}{|c|}{ Mean (SD) at baseline } & \multicolumn{3}{|c|}{ Mean change from baseline at mid-trial } & \multicolumn{3}{|c|}{ Mean change from baseline at trial end } \\
\hline & $\begin{array}{l}\text { General } \\
\text { practice } \\
(n=140)\end{array}$ & $\begin{array}{l}\text { Hospital } \\
(n=126)\end{array}$ & $\begin{array}{l}\text { General } \\
\text { practice } \\
(n=140)\end{array}$ & $\begin{array}{l}\text { Hospital } \\
(n=126)\end{array}$ & $\begin{array}{c}\text { Difference } \\
\text { (95\% confidence } \\
\text { interval) }\end{array}$ & $\begin{array}{l}\text { General } \\
\text { practice } \\
(n=137)\end{array}$ & $\begin{array}{l}\text { Hospital } \\
(n=119)\end{array}$ & $\begin{array}{l}\text { Difference } \\
\text { (95\% confidence } \\
\text { interval) }\end{array}$ \\
\hline \multicolumn{9}{|l|}{ SF-36 subscales: } \\
\hline Physical functioning & $73.1(24.4)$ & $73.7(24.4)$ & 0.1 & -1.4 & $1.5(-1.8$ to 4.9$)$ & -1.6 & -4.7 & $3.1(-1.1$ to 7.5$)$ \\
\hline Pain & $77.8(22.0)$ & $81.3(23.2)$ & -0.8 & -2.7 & $1.8(-3.5$ to 7.3$)$ & -0.6 & -4.4 & $3.8(-1.5$ to 9.2$)$ \\
\hline $\begin{array}{l}\text { Social functioning } \\
\text { Role functioning: }\end{array}$ & $78.4(17.2)$ & $77.2(19.0)$ & -2.8 & 0.3 & $-3.1(-7.7$ to 1.4$)$ & -4.8 & -3.0 & $-1.8(-7.2$ to 3.5$)$ \\
\hline Physical & $70.0(40.1)$ & $69.9(40.3)$ & 5.5 & -0.3 & $5.8(-4.1$ to 15.8$)$ & 5.2 & 1.0 & $4.1(-5.6$ to 13.9$)$ \\
\hline Emotional & $70.7(34.6)$ & $77.6(35.2)$ & 1.5 & 0.9 & $0.6(-8.7$ to 10.1$)$ & 1.9 & 0.1 & $1.8(-7.3$ to 10.8$)$ \\
\hline Mental health & $77.4(16.2)$ & $79.5(17.9)$ & -0.4 & 0.4 & $-0.8(-4.3$ to 2.7$)$ & -1.6 & -2.1 & $0.5(-4.1$ to 5.1$)$ \\
\hline Vitality & 57.1 (22.2) & $56.5(22.7)$ & 1.0 & -0.4 & $1.4(-2.7$ to 5.5$)$ & 1.3 & -2.5 & $3.8(-0.7$ to 8.3$)$ \\
\hline General health perception & $70.2(21.2)$ & $69.3(21.9)$ & 0.9 & -1.9 & $2.8(-1.1$ to 6.9$)$ & -2.0 & -2.6 & $0.6(-3.6$ to 4.8$)$ \\
\hline \multicolumn{9}{|l|}{ EORTC symptom scales: } \\
\hline Fatigue & $25.9(18.7)$ & $25.5(20.6)$ & 1.8 & 1.0 & $0.8(-3.1$ to 4.7$)$ & 1.5 & 3.7 & $-2.2(-6.5$ to 2.2$)$ \\
\hline Appetite loss & $8.1(18.4)$ & $3.8(12.3)$ & -1.2 & 0.5 & $-1.8(-5.8$ to 2.2$)$ & 1.4 & 4.1 & $-2.7(-7.4$ to 2.3$)$ \\
\hline Pain & $20.0(21.8)$ & $16.8(21.4)$ & -0.4 & 3.7 & $-4.1(-9.0$ to 0.9$)$ & 0.1 & 2.7 & $-2.6(-8.0$ to 2.8$)$ \\
\hline Dyspnoea & $20.8(25.5)$ & $16.7(21.8)$ & 1.0 & 2.7 & $-1.7(-6.5$ to 3.1$)$ & 3.0 & 7.6 & $-4.6(-9.8$ to 0.6$)$ \\
\hline Sleep disturbance & 30.8 (31.9) & $25.6(29.9)$ & -1.0 & 1.3 & $-2.3(-8.8$ to 4.1$)$ & -1.7 & 2.0 & $-3.7(-10.4$ to 2.9$)$ \\
\hline HADS anxiety scale & $5.1(3.5)$ & $4.8(3.8)$ & 0.2 & -0.1 & $0.3(-0.4$ to 0.9$)$ & 0.3 & -0.1 & $0.4(-0.3$ to 1.2$)$ \\
\hline HADS depression scale & $2.9(2.8)$ & $3.1(3.1)$ & 0.5 & -0.1 & $0.6(0.1 \text { to } 1.2)^{\star}$ & 0.6 & 0.2 & $0.4(-0.2$ to 1.1$)$ \\
\hline
\end{tabular}

Baseline scores relate to patients responding at mid-trial. For some subscales data were incomplete.

HADS = Hospital anxiety and depression scale.

$* P<0.05$.

There was a small deterioration in quality of life for both groups during the trial. Specifically, in the hospital group there were small but statistically significant increases in mean EORTC symptom scores for fatigue (3.7, 0.8 to 6.6$)$, dyspnoea $(7.6,3.8$ to 11.4$)$, and appetite loss $(4.1,0.8$ to 7.3$)$, and a decrease in the SF-36 physical functioning score $(-4.7,-7.8$ to -1.7$)$. In the general practice group there was a decrease in the mean SF-36 social functioning score $(-4.8,-8.8$ to -0.8$)$. The selected EORTC symptom subscales presented in table 4 are those most relevant to breast cancer recurrence; changes in other subscales were small and not statistically significant.

\section{Discussion}

CLINICAL DIAGNOSIS

This trial was designed primarily to evaluate whether general practice follow up results in delay in diagnosing recurrence and reinitiating specialist care. This main endpoint was chosen because there is no reason to believe that the place of follow up will affect recurrence rates or survival. However, delay in confirming a diagnosis of recurrence and reinitiating specialist care may result in an increase in morbidity.

Our findings give no indication that general practice follow up is associated with increased time to diagnosis, even taking the conservative endpoint of effective re-entry into the hospital system. They emphasise the point that most recurrences, including local and regional recurrence, are detected by women themselves in the interval between follow up appointments who then present to their general practitioners. The study provides only limited information about local recurrence. In all three cases of purely local recurrence in the general practice group, re-entry to the hospital system from general practice took four weeks or more. In every case the delay was primarily administrative. Such administrative delays can be avoided by good organisation and quality control, particularly if the pressure on outpatient clinics can be relieved by reducing the burden of routine follow up.

HEALTH RELATED QUALITY OF LIFE

As expected, there was an increase in mean physical symptom scores in the trial cohort, consistent with the development of recurrence during the 18 month follow up period. However, there was no important or signifi- cant difference between the hospital and general practice groups in general health or social and emotional functioning measured by SF- 36 scales or in levels of anxiety on the hospital anxiety and depression scale.

\section{CONCLUSIONS}

The difference in the number of recurrences in the two allocation groups is consistent with chance. However, the trial has one important limitation which must be recognised: as there was no common clinical examination at the end of the trial, it could be argued that there were unrecognised cases of recurrence in the general practice group which would have been elicited by examination at the hospital. With respect to local recurrence, women in both groups were receiving mammography and there were more cases of locoregional recurrence detected in the general practice group than the hospital group. With respect to metastatic recurrence, most distant recurrences are symptomatic at the time of diagnosis, although the possibility that hospital clinics are better at eliciting metastatic symptoms cannot be excluded by our design.

If delegation of follow up care to general practice is accepted to be desirable, would general practitioners undertake it and would women accept it? We, and others, have reported that the vast majority of general practitioners wish to provide follow up for their patients with breast cancer if their concerns about increased workload can be met, if clear guidelines for follow up can be given, and if assurances are given that patients will be seen urgently by the specialist on an open access basis. Not all women would opt for general practice follow up. While two thirds of eligible patients agreed to participate in this study it is important to recognise that perhaps one third of women will prefer to be seen in specialist clinics for routine follow up, and their preferences must be taken into account in formulating policy.

We thank Jean Pugh, Jo Horler, Christine Southwell, and Sally Black for their excellent and dedicated work as research nurses and Drs John Clements and Graham Cradduck for advice and support as general practitioner liaisons. We thank the many surgeons, oncologists, and general practitioners whose commitment made this research possible. We particularly thank the women with breast cancer who participated in this research. 


\section{Key messages}

- After primary treatment is completed women with breast cancer are usually followed up for some years

- Broadly, the goals of follow up are to detect recurrence, detect new contralateral primaries, and provide psychosocial support

- For women who are free of disease, general practice follow up was not associated with increased time to diagnosis of recurrence or deterioration in health related quality of life

Funding: At the time of the research EG was a fellow of the National Cancer Institute of Canada supported with funds from the Canadian Cancer Society. PY is supported by the Imperial Cancer Research Fund. The research was funded by the Department of Health for England and Wales with a generous contribution from Ballakermean School on the Isle of Man and support from the general practice research group of the Imperial Cancer Research Fund.

Conflict of interest: None.

1 Dewar JA, Kerr GR. Value of routine follow up of women treated for early carcinoma of the breast. BMF 1985;291:1464-7.

2 Loomer L, Brockschmidt JK, Muss HB, Saylor G. Postoperative follow up of patients with early breast cancer. Cancer 1991;67:55-60.

3 Tomiak E, Piccart M. Routine follow up of patients after primary therapy for early breast cancer: changing concepts and challenges for the future. Ann Oncol 1993;4:199-204.

4 Richert-Boe KE. Heterogeneity of cancer surveillance practices among medical oncologists in Washington and Oregon. Cancer 1995;75:2605-12. Schapira D, Urban N. A minimalist policy for breast cancer surveillance. IAMA 1991;265:380-2.

Wertheimer $M$. Against minimalism in breast cancer follow up. $\varsubsetneqq A M A$ 1991;265:396-7.

7 Loprinzi C. It is now the age to define the appropriate follow up of primary breast cancer patients. f Clin Oncol 1994;12:881-3.
8 Pandya KJ, McFadden ET, Kalish LA, Tormey DC, Taylor SG, Falkson G. A retrospective study of the earliest indicators of recurrence in patients in Eastern Cooperative Oncology Group adjuvant chemotherapy trials for breast cancer. Cancer 1985;55:202-5.

9 Scanlon EF, Oviedo M, Cunningham MP, Caprini JA, Khandekar JD, Cohen E, et al. Preoperative and follow up procedures on patients with breast cancer. Cancer 1980;46:977-9.

10 Broyn T, Froyen J. Evaluation of routine follow up after surgery for breast carcinoma. Acta Chir Scand 1982;148:401-4.

11 Winchester DP, Sener SF, Khandekar JD, Oviedo MA, Cunningham MP, Caprini JA, et al. Symptomology as an indicator of recurrent or metastatic breast cancer. Cancer 1979;43:956-60.

12 Zwaveling A, Albers GHR, Felthuis W, Hermans J. An evaluation of routine follow up for detection of breast cancer recurrences. I Surg Oncol 1987;34:194-7.

13 Rosselli Del Turco M, Palli D, Cariddi A, Ciatto S, Pacini P, Distante V. Intensive diagnositic follow up after treatment of primary breast cancer. IAMA 1994:271:1593-7.

14 GIVIO Investigators. Impact of follow up testing on survival and health-related quality of life in breast cancer patients. $\mathscr{f} A M A$ 1994;271:1587-92.

15 Dewar J. Follow up in breast cancer: a suitable case for reappraisal. $B M \mathcal{F}$ 995;310:685.

16 James ND, Guerrero D, Brada M. Who should follow up cancer patients? Nurse specialist based outpatient care and the introduction of a phone clinic system. Clinical Oncology 1994;6:283-7.

17 Hollen PJ, Hobbie W. Establishing comprehensive specialty follow up clinics for long term survivors of cancer. Support Care Cancer 1995;3:40-4.

18 Grunfeld E, Mant D, Vessey MP, Fitzpatrick R. Specialist and general practice views on routine follow up of breast cancer patients in general practice. Fam Pract 1995;12:60-5.

19 Worster A, Bass MJ, Wood ML. A willingness to follow breast cancer: a survey of family physicians. Can Fam Phys 1996;42:263-8.

20 Ware JE, Snow KK, Kosinski M, Gandek B. SF-36 health survey: manual and interpretation guide. Boston: Health Institute, New England Medical Center, 1993.

21 Aaronson NK, Ahmedzai S, Bergman B, Bullinger M, Cull A, Duez NJ, et al. The European Organisation for Research and Treatment of Cancer QLQ-C30: a quality of life instrument for use in international clinical trials in oncology. I Natl Cancer Inst 1993;85:365-76.

22 Zigmond AS, Snaith RP. The hospital anxiety and depression scale. Acta Psychiatr Scand 1983;67:361-70.

23 Altman DG. How large a sample? In: Gore SM, Altman DG, eds. Statistics in practice. 8th ed. London: BMJ Publishing, 1991.

24 Early Breast Cancer Trialists' Collaborative Group. Systemic treatment of early breast cancer by hormonal cytotoxic or immune therapy. Lancet 1992;339:1-15, 71-85.

25 Gardner SB, Winter PD, Gardner MJ. CIA. London: BMJ Publishing, 1991.

(Accepted 29 Fuly 1996)

\section{Deprivation payments to general practitioners: limitations of census data}

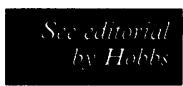

\section{F Azeem Majeed, David Martin, Tim Crayford}

The census data from which deprivation payments have been calculated since June 1995 suffer from limitations including underenumeration; under counting of homeless people and refugees, and artefactual errors because of the way in which the 1991 census data were tabulated. These limitations reduced the fairness of the changes that many practices experienced in their deprivation payments. The validity of the current system of deprivation payments would be improved if these limitations were borne in mind when allocating payments to practices and if enumeration districts were used as the basis of payments rather than electoral wards.

In June 1995 the Department of Health started to use 1991 census data to allocate deprivation payments to general practices, and for many practices this resulted in large changes in their deprivation payments. ${ }^{1}$ Because of changes in social deprivation between the 1981 and 1991 censuses, some changes in the deprivation payments to general practices were inevitable. However, the census data on which deprivation payments are based have limitations. We discuss the potential effect of these limitations on deprivation payments.

\section{Underenumeration}

High levels of underenumeration occurred in areas with deprived, mobile populations, such as inner London. ${ }^{2}$ The Jarman variables most strongly influenced by underenumeration will have been "unskilled," "unemployed," and "ethnicity." The Department of Health made no attempt to estimate the effect of underenumeration on Jarman scores, and it is not known what effect adjusting for underenumeration would have on deprivation payments to general practices in areas with high levels of underenumeration. Furthermore, inner city areas-and inner London in particular-have many refugees and homeless people, categories that were not well recorded in the census. These patients may add considerably to the workload of general practitioners, but the census will contain little information on them. For this reason, practices will not receive any additional deprivation payments to compensate them for the increased workload involved in looking after homeless people and refugees.

\section{Artefactual errors}

Census data contain inaccuracies because of the way in which the data are tabulated. ${ }^{3}$ Census variables, such as those included in the Jarman score, are calculated from tables of census data. The same Jarman variable can often be calculated from data in different tables, and different tables can give slightly different values of the Jarman variables. Moreover, one of the Jarman variables, unskilled, is based on an analysis of $10 \%$ of census records and is therefore subject to sampling error. These artefactual errors will have no effect on most census wards, but in wards that are close to the cut off points for the different levels of payment the errors may be sufficient to move a census ward up or down one 